\title{
Separation and migration behavior of structurally related phenothiazines in cyclodextrin-modified capillary zone electrophoresis
}

\author{
Kuo-Hsing Chen, Ching-Erh Lin*, Wei-Ssu Liao, Wann-Yin Lin, Yu-You Hsiao \\ Department of Chemistry, National Taiwan University, P.O. Box 23-34, 1 Roosevelt Road Section 4, Taipei 10674, Taiwan
}

\begin{abstract}
The influences of buffer $\mathrm{pH}$ and the concentration of $\beta$-cyclodextrins ( $\beta$-CDs) on the separation and migration behavior of 13 structurally related phenothiazines in CD-modified capillary zone electrophoresis (CD-CZE) using a phosphate background electrolyte at low $\mathrm{pH}$ were investigated. We focused on the separation of these phenothiazines, including the enantiomers of chiral analytes, with the use of $\beta-C D$ and hydroxypropyl- $\beta-C D(H P-\beta-C D)$ as electrolyte modifiers or chiral selectors at concentrations less than $8 \mathrm{~m} M$. The results indicate that the interactions of phenothiazines with $\beta$-CDs are very strong and that effective separations of 13 analytes can be achieved with addition of $0.3 \mathrm{~m} M \beta-\mathrm{CD}$ or $0.5 \mathrm{~m} M \mathrm{HP}-\beta-\mathrm{CD}$ in a phosphate buffer at $\mathrm{pH}$ 3.0. Binding constants of phenothiazines to $\beta$-CDs were evaluated for a better understanding of the interactions of phenothiazines with $\beta$-CDs.
\end{abstract}

(C) 2002 Elsevier Science B.V. All rights reserved.

Keywords: Migration behaviour; Phenothiazines; Cyclodextrins

\section{Introduction}

In capillary electrophoresis (CE), cyclodextrins (CDs) are widely used as chiral selectors for enantioseparation or frequently used as electrolyte modifiers to affect the separation and selectivity of analytes with closely related structures [1-3]. In the separation of analytes by capillary zone electrophoresis (CZE), buffer $\mathrm{pH}$ is an important parameter because it determines the extent of the ionization of analytes. When manipulation of this parameter can no longer enhance the selectivity, addition of CDs to an electrophoretic system is often considered to affect

\footnotetext{
*Corresponding author. Tel.: + 886-2-2363-5357; fax: + 886-22363-6359.

E-mail address: celin@ccms.ntu.edu.tw (C.-E. Lin).
}

the separation and selectivity so that a successful separation can be achieved.

Phenothiazines are a group of basic drugs with different substituents attached at the 2-position $\left(\mathrm{R}_{2}\right)$ and 10-position $\left(\mathrm{R}_{10}\right)$ of the phenothiazine ring. The $\mathrm{R}_{10}$ substituent is an alkyl piperazine group, a piperidine moiety, or an aliphatic side chain containing an amino group. These compounds are used as antipsychotic and neuroleptic agents or antihistamines. Fig. 1 depicts the structures of the 13 phenothiazines studied.

Phenothiazines, and the enantiomers as well, have previously been separated by HPLC [4-11] and CE [12-22]. Six out of 14 phenothiazines have been baseline separated in CZE with reversed electroosmotic flow using a Tris-formic acid buffer containing a fluorinated cationic surfactant FC 135 at $\mathrm{pH}$ 3.5 [12]. Ten phenothiazines, together with the 


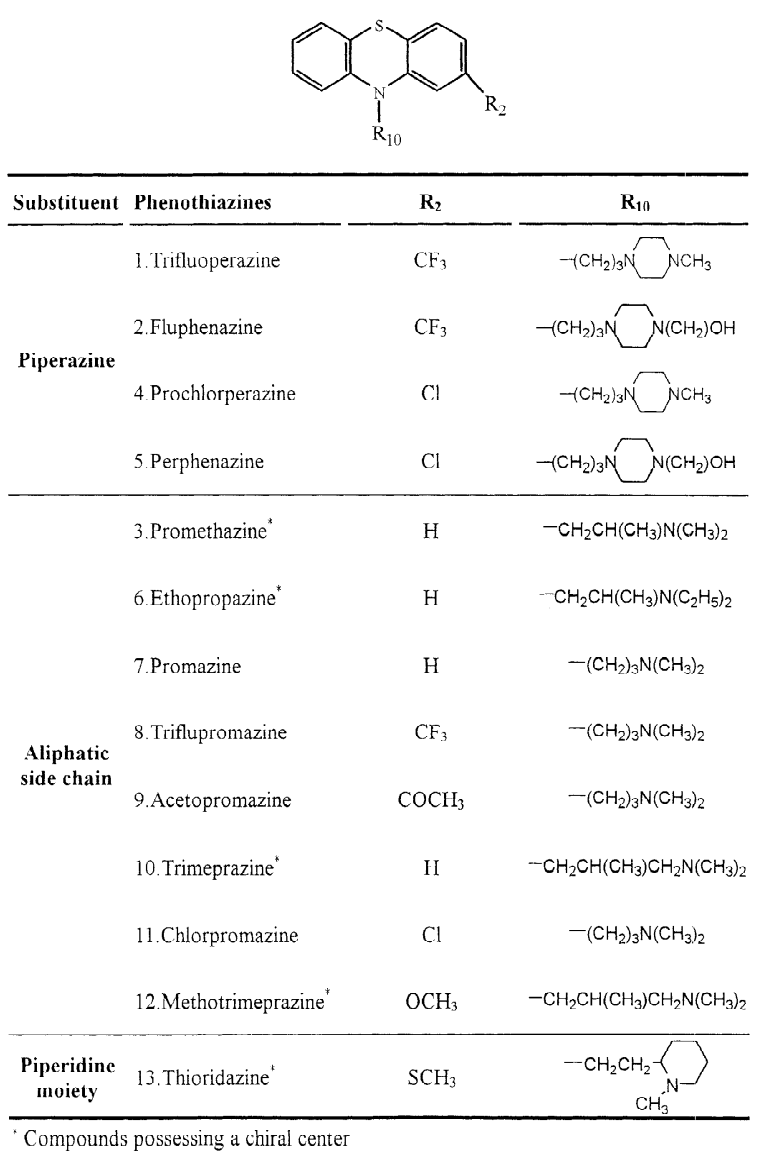

Fig. 1. Structures of the 13 phenothiazines studied.

enantiomers of trimeprazine, were effectively separated with addition of 8,15 and $22 \mathrm{~m} M$ hydroxypropyl- $\beta-\mathrm{CD}$ (HP- $\beta-\mathrm{CD}$ ) in a phosphate buffer at $\mathrm{pH} 2.5$ [17]. It should be pointed out that the enantiomers of promethazine could not be separated with HP- $\beta-C D$ and the enantiomers of thioridazine could not be resolved with HP- $\beta-C D$ at a concentration of $8 \mathrm{~m} M$ or greater.

In our previous paper [21], the enantiomers of promethazine, ethoprapazine, trimeprazine and thioridazine were effectively separated by CZE using HP- $\beta-C D$ and $\beta-C D$ as chiral selectors at relatively low concentrations in a phosphate buffer at $\mathrm{pH} 3.5$. As strong interactions were found to occur between phenothiazines and $\beta$-CDs, optimal CD concentrations for effective enantioseparations of phenothiazines were determined to be in the range $0.2-1.6$ $\mathrm{m} M$ and $0.05-1.2 \mathrm{~m} M$ with the use of HP- $\beta-\mathrm{CD}$ and $\beta-C D$, respectively, as a chiral selector. The results also suggested that effective separations of structurally related phenothiazines would be achievable by CZE with the use of $\beta$-CDs as electrolyte modifiers at a concentration much lower than $8 \mathrm{~m} M$.

On the other hand, separation of phenothiazines by micellar electrokinetic chromatography (MEKC) was rarely reported [12]. Nine out of 14 phenothiazines were separated with $\beta-\mathrm{CD}$ as an electrolyte modifier using a Tris-acetate buffer containing a fluorinated cationic surfactant and CTAB (cetyltrimethylammonium bromide) at $\mathrm{pH} 5.0$ [12]. Very recently, enantioseparations of five phenothiazines in cyclodextrin (CD)-modified micellar electrokinetic chromatography were investigated using a citrate buffer containing tetradecyltrimethylammonium bromide (TTAB) as a cationic surfactant at low $\mathrm{pH}$. $\beta$ Cyclodextrin ( $\beta-C D)$ and hydroxylpropyl- $\beta-C D$ $(\mathrm{HP}-\beta-\mathrm{CD})$ were selected as chiral selectors. Effective enantioseparation of thioridazine is simultaneously achievable with that of trimeprazine and promethazine or ethopropazine in MEKC with addition of either $\beta-\mathrm{CD}$ or HP- $\beta-\mathrm{CD}$, respectively, to a micellar citrate buffer containing TTAB at $\mathrm{pH} 3.5$ [22].

In this work, the separation and migration behavior of 13 structurally related phenothiazines in CZE using HP- $\beta-C D$ and $\beta-C D$ as electrolyte modifiers were investigated. We focus on the influences of buffer $\mathrm{pH}$ and the $\mathrm{CD}$ concentration less than $8 \mathrm{mM}$ on the separation and selectivity. The interactions of phenothiazines with $\beta$-CDs are studied and the binding constants of phenothiazines to $\beta$-CDs are evaluated. It is hoped that the separation and migration behavior of phenothiazines can be better understood.

\section{Experimental}

\subsection{Apparatus}

All CE separations were carried out on a Beckman P/ACE System MDQ equipped with a photodiode array detector for absorbance measurements at 240 nm (Beckman Coulter, Fullerton, CA, USA). Uncoated fused-silica capillaries purchased from Poly- 
micro Technologies (Phoenix, AZ, USA) were used. The dimensions of the capillary were $60.2 \mathrm{~cm} \times$ $50 \mu \mathrm{m}$ I.D. The effective length of the capillary was $50 \mathrm{~cm}$ from the injection end of the capillary. The CE system was interfaced with a microcomputer and a laser printer. System Gold software from Beckman was used for data acquisition. For $\mathrm{pH}$ measurements, a pH meter (Suntex Model SP-701, Taipei, Taiwan) was employed with a precision of $\pm 0.01 \mathrm{pH}$ unit.

\subsection{Chemicals and reagents}

Thirteen phenothiazines were obtained from Sigma (St Louis, MO, USA). $\beta-C D$ was obtained from Merck (Darmstadt, Germany) and HP- $\beta-C D$ from Sigma-Aldrich (St Louis, MO, USA). All other chemicals were of analytical grade. Deionized water was prepared with a Milli-Q system (Millipore, Bedford, MA. USA).

Standard solutions of phenothiazines at a concentration of $10 \mu \mathrm{g} / \mathrm{ml}$ were prepared by dissolving analytes in an aqueous solution. The $\mathrm{pH}$ of a phosphate buffer was adjusted to the desired $\mathrm{pH}$ value by mixing various proportions of a certain concentration of trisodiumphosphate solution with the same concentration of phosphoric acid. All buffer solutions, freshly prepared weekly and stored in a refrigerator before use, were filtered through a membrane filter $(0.22 \mu \mathrm{m})$.

\subsection{Electrophoretic procedure}

When a new capillary was used, the capillary was washed for $30 \mathrm{~min}$ with $1.0 M \mathrm{NaOH}$ solution, followed by $30 \mathrm{~min}$ with deionized water at $25^{\circ} \mathrm{C}$. Before each injection, the capillary was prewashed for 3 min with running buffer and postwashed for 3 min with deionized water, 3 min with $0.1 M$ $\mathrm{NaOH}$, and 5 min with deionized water to maintain proper reproducibility of run-to-run injections. Sample injections were done in hydrodynamic mode over $5 \mathrm{~s}$ under a pressure of 1.0 p.s.i. at $25^{\circ} \mathrm{C}$. The measurements were run at least in triplicate to ensure reproducibility. An applied voltage of $20 \mathrm{kV}$ for phosphate buffer was selected to keep the total current less than $70 \mu \mathrm{A}$. The detection wavelength was set at $240 \mathrm{~nm}$. Peak identification was conducted by spiking with the analyte to be identified. Mesityl oxide was used as neutral marker. The relative standard deviation of migration time was less than $0.6 \%(n=5)$.

\subsection{Mobility calculations}

The electrophoretic mobility of analytes was calculated from the observed migration times with the equation:

(1) $\mu_{\mathrm{ep}}=\mu-\mu_{\mathrm{eo}}=\frac{L_{\mathrm{d}} L_{\mathrm{t}}}{V}\left(\frac{1}{t_{\mathrm{m}}}-\frac{1}{t_{\mathrm{e}_{\mathrm{o}}}}\right)$

where $\mu_{\mathrm{ep}}$ is the electrophoretic mobility of the analyte tested, $\mu$ is the apparent mobility, $\mu_{\mathrm{eo}}$ is the electroosmotic mobility, $t_{\mathrm{m}}$ is the migration time measured directly from the electropherogram, $t_{\mathrm{eo}}$ is the migration time for an unchanged solute, $L_{\mathrm{t}}$ is the total length of capillary, $L_{\mathrm{d}}$ is the length of capillary between injection and detection, and $V$ is the applied voltage.

\section{Results and discussion}

\subsection{Separation of phenothiazines in CZE}

\subsubsection{Influence of buffer $p H$}

In CZE, buffer $\mathrm{pH}$ plays an important role in the separation of ionizable analytes because it determines the extent of the ionization of each individual analyte [23]. Therefore, manipulation of buffer $\mathrm{pH}$ usually becomes a key strategy to optimize a separation. For the separation of phenothiazines, the $\mathrm{pH}$ of the buffer was often chosen at low $\mathrm{pH}$ $[12,17,21,22]$ because the electrophoretic mobility of phenothiazines with three different groups of $R_{10}$ substituents varies in three different ranges. Fig. 2 shows the variations of the electrophoretic mobility of phenothiazines as a function of buffer $\mathrm{pH}$ in the range 2.5-5.5 using a phosphate background electrolyte $(40 \mathrm{mM})$. As can be seen, the electrophoretic mobility of phenothiazines with piperazine substituents decreases drastically in the $\mathrm{pH}$ range studied, while the electrophoretic mobility of phenothiazines with substituents having a piperidine moiety and an aliphatic side chain remains almost constantly in the $\mathrm{pH}$ range $2.5-4.0$, then decreases 


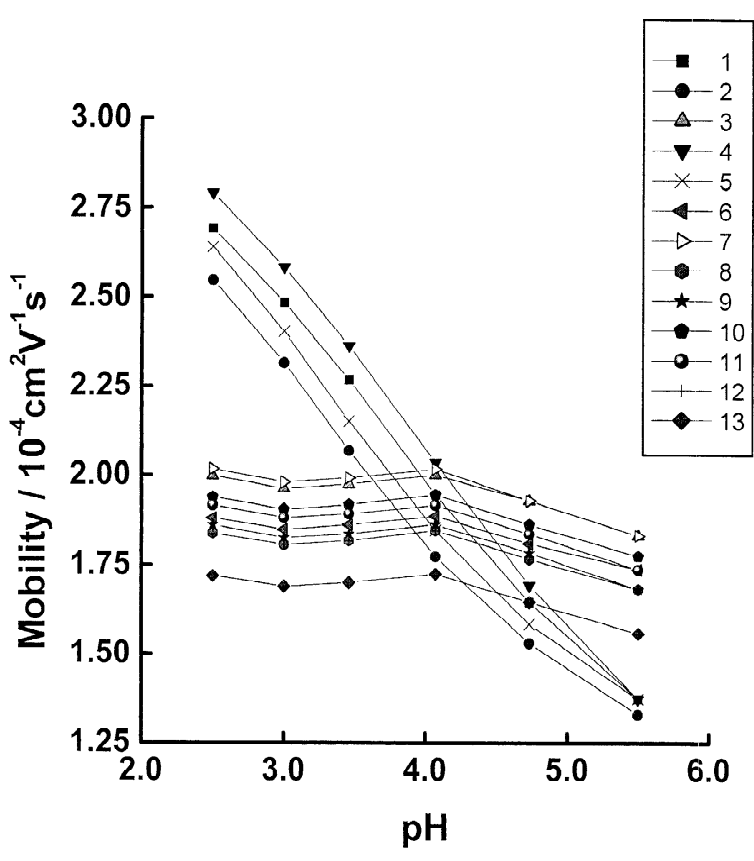

Fig. 2. Variations of the electrophoretic mobility of phenothiazines as a function of buffer $\mathrm{pH}$ in the range 2.5-5.5 using a phosphate buffer $(40 \mathrm{mM})$. Capillary, $60.2 \mathrm{~cm} \times 50 \mu \mathrm{m}$, I.D.; Sample concentration, $10 \mu \mathrm{g} / \mathrm{ml}$; Detection wavelength, $240 \mathrm{~nm}$; Other operating conditions, $20 \mathrm{kV}, 25^{\circ} \mathrm{C}$. Curve identification, $1=$ trifluoperazine (filled box); $2=$ fluphenazine (filled circle); $3=$ promethazine (filled upright triangle); $4=$ prochlorperazine (filled inverted triangle); $5=$ perphenazine (diagonal cross); $6=$ ethopropazine (filled left-facing triangle); $7=$ promazine (filled right-facing triangle); $8=$ triflupromazine (filled hexagon); $9=$ acetopromazine (filled star); $10=$ trimeprazine (filled pentagon); $11=$ chlorpromazine $\quad($ filled circle with bright spot); 12= methotrimeprazine (upright cross); $13=$ thioridazine (filled lozenge).

gradually in the range 4.0-5.5. The separability of phenothiazines becomes worse at $\mathrm{pH}$ above 3.5 because phenothiazines with piperazine substituents may comigrate with phenothiazine with substituents having an aliphatic side chain at a $\mathrm{pH}$ in the range $3.8-5.0$ or merge together at a $\mathrm{pH}$ in the range 5.5-7.5. Therefore, buffer $\mathrm{pH}$ is optimally selected in the range $2.5-3.5$. The results clearly indicate that phenothiazines with piperazine substituents behave quite differently from those with substituents having an aliphatic side chain and a piperidine moiety.

The measurements of the electrophoretic mobility of phenothiazines as a function of buffer $\mathrm{pH}$ in the range $2.5-11.5$ were conducted in order to determine the $\mathrm{p} K_{\mathrm{a}}$ values and the limiting electrophoretic mobility of phenothiazines. The first $\mathrm{p} K_{\mathrm{a}}$ values determined for phenothiazines with piperazine substituents are in the range 3.60-3.86 [24].

\subsubsection{Influence of $H P-\beta-C D$ concentration}

As illustrated previously [21], the addition of HP$\beta-C D$ to the electrophoretic system can enlarge the separation window so that better separability can be obtained at low CD concentrations. However, the separation window becomes more and more restricted at higher CD concentrations. Therefore, for an optimal separation, CD concentration should be properly selected.

To illustrate clearly, the variations of the electrophoretic mobility of eight achiral and five chiral phenothiazines, respectively, as a function of HP- $\beta$ $\mathrm{CD}$ concentration in the range $0-8 \mathrm{~m} M$ using a phosphate buffer $(40 \mathrm{mM})$ at $\mathrm{pH} 3.0$ are shown in Fig. 3. The electrophoretic mobility of achiral phenothiazines (Fig. 3A) decreases drastically with increasing HP- $\beta-\mathrm{CD}$ concentration, especially in the range $0-2 \mathrm{~m} M$, as described previously for chiral phenothiazines (Fig. 3B) [21]. This phenomenon indicates that these phenothiazines interact strongly with HP- $\beta-C D$.

It is interesting to note that the electrophoretic mobility of four achiral phenothiazines with piperazine substituents and that of the other four achiral analytes with aliphatic side chain substituents were confined to two distinctly narrow ranges as HP- $\beta-C D$ concentration increased from 2 to $8 \mathrm{~m} M$. The electrophoretic mobilities of phenothiazines with piperazine substituents at 8 and $0 \mathrm{~m} M$ HP- $\beta-C D$, respectively, are greater than those of phenothiazines with substituents having an aliphatic side chain. Obviously, this phenomenon is related to the $\mathrm{p} K_{\mathrm{a}}$ values of phenothiazines, which control the extent of the ionization of these two groups of phenothiazines at $\mathrm{pH}$ 3.0. The restricted mobility of phenothiazines at higher HP- $\beta-C D$ concentrations reveals that separations of phenothiazines carried out with HP- $\beta-C D$ at a concentration equal to or greater than $8 \mathrm{~m} M$, reported previously by Boer et al. [15], were not under the optimized conditions. Thus better separability of phenothiazines can be obtained at concentrations much lower than $8 \mathrm{~m} M$.

Fig. 4 shows the electropherograms of phenothi- 
(A)

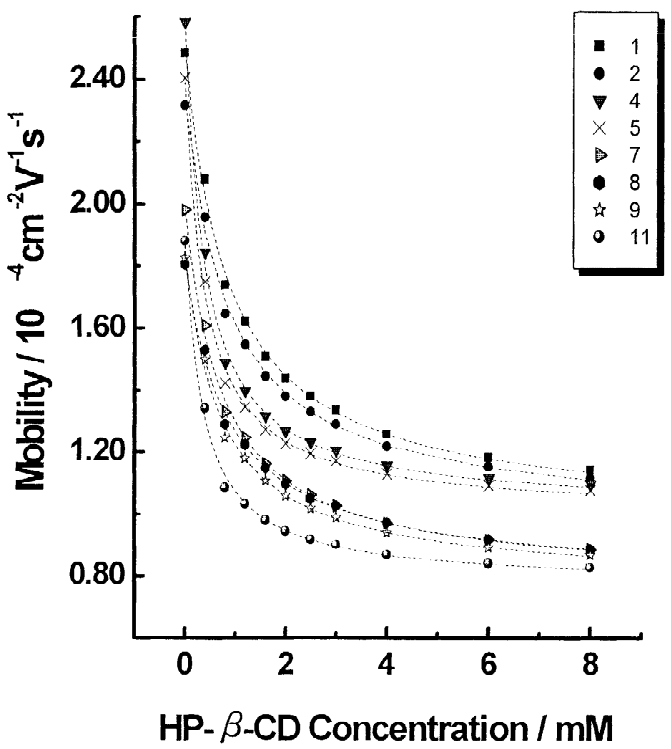

(B)

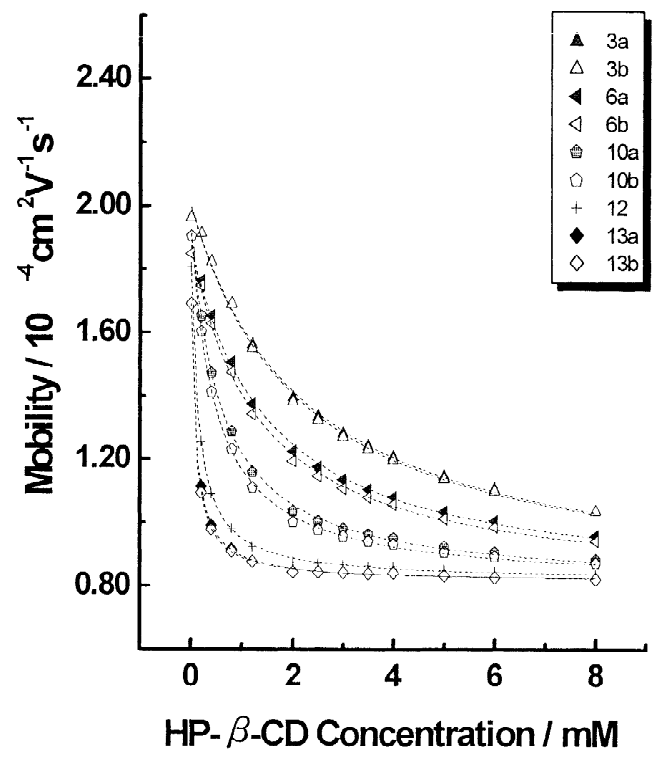

Fig. 3. Variations of the electrophoretic mobility of phenothiazines as a function of HP- $\beta-C D$ concentration in the range $0-8 \mathrm{~m} M$ using a phosphate buffer $(40 \mathrm{mM})$ at $\mathrm{pH}$ 3.0: (A) eight achiral analytes, (B) five chiral analytes. Other operating conditions and curve identification are the same as for Fig. 2.

azines obtained with addition of $\mathrm{HP}-\beta-\mathrm{CD}$ at a concentration of $0,0.5$ and $1.0 \mathrm{mM}$ using a phosphate buffer at $\mathrm{pH}$ 3.0. Comparing the electropherograms of phenothiazines obtained in the presence of HP- $\beta-C D$ at 0.5 and $1.0 \mathrm{~m} M$ with that of phenothiazines obtained in the absence of HP- $\beta-C D$, it is clearly indicated that addition of HP- $\beta-C D$ at low concentrations can increase the separability of phenothiazines. Complete separation of the 13 phenothiazines studied was achieved with addition of HP- $\beta$-CD at $0.5 \mathrm{~m} M$ in a phosphate buffer at $\mathrm{pH}$ 3.0. The enantiomers of ethopropazine and trimeprazine were baseline separated, but the enantiomers of thioridazine were partially resolved with addition of HP- $\beta-C D 0.5 \mathrm{~m} M$. With addition of $1.0 \mathrm{~m} M$ HP- $\beta$ $\mathrm{CD}$, the enantioresolution of thioridazine was almost lost. This phenomenon is understandable because the interaction of thioridazine with HP- $\beta-C D$ is comparatively much stronger than the other phenothiazines studied and the optimal CD concentration for enantioseparation expected is less than $0.2 \mathrm{mM}$ [21]. The separability of phenothiazines decreased with increasing HP- $\beta-C D$ concentration above $1.0 \mathrm{~m} M$. In fact, one of the enantiomers of ethopropazine comi- grated with perphenazine with addition of HP- $\beta-\mathrm{CD}$ at $1.0 \mathrm{~m} M$. Thus, we may conclude that separation of phenothiazines is more advantageous with the use of HP- $\beta$-CD at low concentrations $(<1 \mathrm{mM})$ than at relatively higher concentrations $(>8 \mathrm{mM})$. For a better understanding of the separation and migration behavior of phenothiazines, the binding constants of phenothiazines to HP- $\beta-C D$ are evaluated, which will be discussed later in Section 3.2.

\subsubsection{Influence of $\beta-C D$ concentration}

Fig. 5 shows the variations of the electrophoretic mobility of eight achiral and five chiral phenothiazines, respectively, as a function of $\beta-C D$ concentration in the range $0-6 \mathrm{~m} M$ under the same electrophoretic conditions as in the case of HP- $\beta$ $\mathrm{CD}$. The trends in the variation of the electrophoretic mobility of phenothiazines were similar to those when HP- $\beta-C D$ was used. As the interactions of phenothiazines with $\beta-C D$ are three to four times stronger than those with HP- $\beta-C D$, more drastic variations in the electrophoretic mobility curves are observed with $\beta-C D$, in comparison to those observed with HP- $\beta-C D$. The enlargement of the 


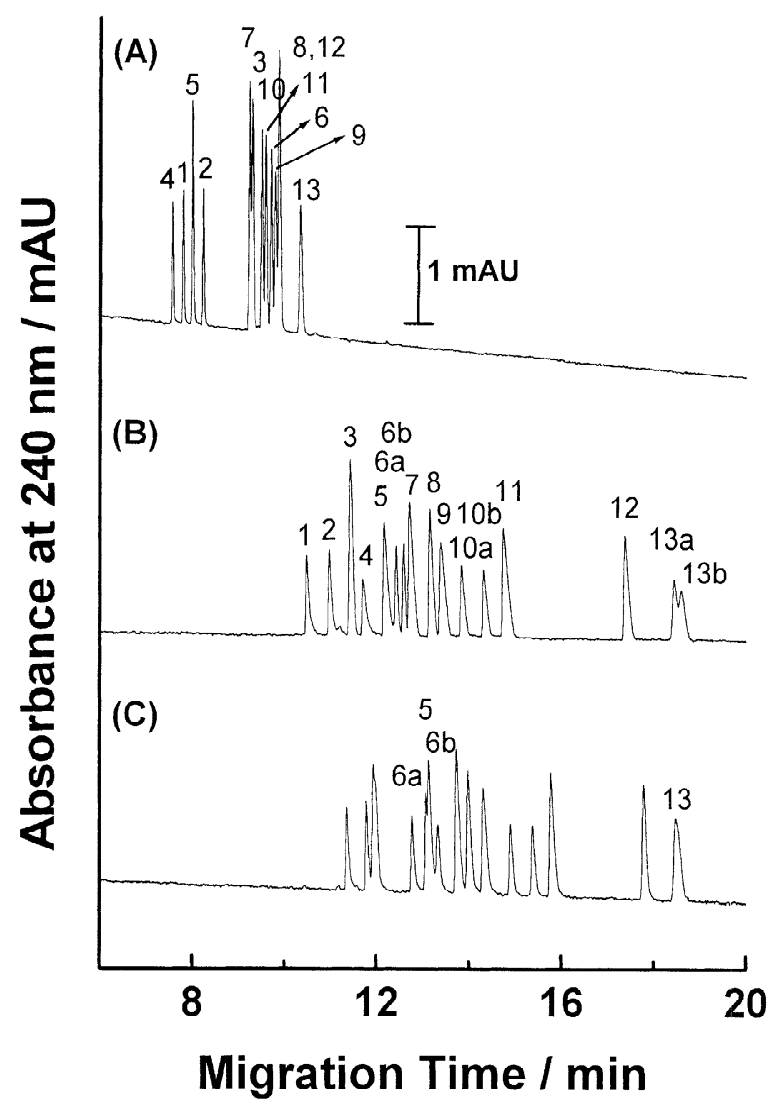

Fig. 4. Electropherograms of phenothiazines obtained with addition of HP- $\beta-C D$ at (A) $0 \mathrm{mM}$, (B) $0.5 \mathrm{mM}$, and (C) $1.0 \mathrm{mM}$ using a phosphate buffer $(40 \mathrm{~m} M)$ at $\mathrm{pH} 3.0$.

separation window occurs at lower concentrations with $\beta$-CD than with HP- $\beta-C D$. As show in Fig. 5A, the electrophoretic mobility of four achiral phenothiazines with piperazine substituents and that of the other four achiral analytes with substituents having an alkyl side chain were confined and converged to two distinct ranges, but smaller than those observed in the case of HP- $\beta-C D$, as $\beta-C D$ concentration increased from 1 to $6 \mathrm{~m} M$.

Fig. 6 shows the electropherograms of phenothiazines obtained with addition of $\beta-\mathrm{CD}$ at 0.3 and 1.0 $\mathrm{m} M$ in a phosphate buffer $(40 \mathrm{~m} M)$ at $\mathrm{pH} 3.0$. As illustrated, 13 phenothiazines could be effectively separated with addition of $\beta-\mathrm{CD}$ at a concentration of $0.3 \mathrm{~m} M$. However, peak overlapping between acetopromazine and one of the enantiomers of trimeprazine occurred. The enantiomers of pro- methazine, trimeprazine and thioridazine were effectively resolved with addition of $\beta-\mathrm{CD}$ at $0.3 \mathrm{mM}$. As expected, no enantioresolution of thioridazine was observed with $\beta-C D$ at $1.0 \mathrm{~m} M$. Compared with the separation obtained with addition of $0.3 \mathrm{~m} M \beta-\mathrm{CD}$, the separability of phenothiazines decreases with increasing $\beta-C D$ concentration above $1 \mathrm{~m} M$. As shown in Fig. 6B, separation of 13 phenothiazines is less effective with addition of $\beta-\mathrm{CD}$ at $1 \mathrm{~m} M$ than at $0.3 \mathrm{~m} M$.

\subsection{Evaluation of binding constants}

For a better understanding of the influence of $\beta-C D$ concentration on the separation and migration behavior of these phenothiazines, binding constants of phenothiazines are evaluated based on the dependence of the effective electrophoretic mobility of phenothiazines on the concentration of $\beta$-CDs. At $\mathrm{pH}$ 3.0, the effective electrophoretic mobility of phenothiazines, excluding phenothiazines with piperazine substituents, can be described by the following equation [25-27]:

$\mu_{\mathrm{eff}}=\frac{\mu_{\mathrm{BH}_{2}^{2+}}+K_{\mathrm{BH}_{2}^{2+} \cdot \mathrm{CD}}[\mathrm{CD}] \mu_{\mathrm{BH}_{2}^{2+} \cdot \mathrm{CD}}}{1+K_{\mathrm{BH}_{2}^{2+} \cdot \mathrm{CD}}[\mathrm{CD}]}$

where $\mu_{\mathrm{BH}_{2}^{2+}}$ is the electrophoretic mobility of the second protonated species of an analyte in the absence of $\beta$-CDs, $\mu_{\mathrm{BH}_{2}^{2+} \cdot \mathrm{CD}}$ is the electrophoretic mobility of the inclusion complex formed between the second protonated species of an analyte and $\beta$-CDs, $K_{\mathrm{BH}_{2}^{2+} \cdot \mathrm{CD}}$ is the binding constant of the inclusion complex, and $[\mathrm{CD}]$ is the concentration of free $\beta$-CDs.

It should be pointed out that, owing to strong interactions of phenothiazines with $\beta$-CDs, the concentration of free $\beta$-CDs has to be corrected according to the equation:

$[\mathrm{CD}]=\frac{[\mathrm{CD}]_{\mathrm{t}}}{1+K_{\mathrm{BH}_{2}^{2+} \cdot \mathrm{CD}}\left[\mathrm{BH}_{2}^{2+}\right]}$

where $[\mathrm{CD}]_{\mathrm{t}}$ and $\left[\mathrm{BH}_{2}^{2+}\right]$, respectively, are the analytical concentrations of $\mathrm{CD}$ and the second protonated species of an analyte.

The binding constants of each individual inclusion complex formed between phenothiazine and $\beta$-CDs 
(A)

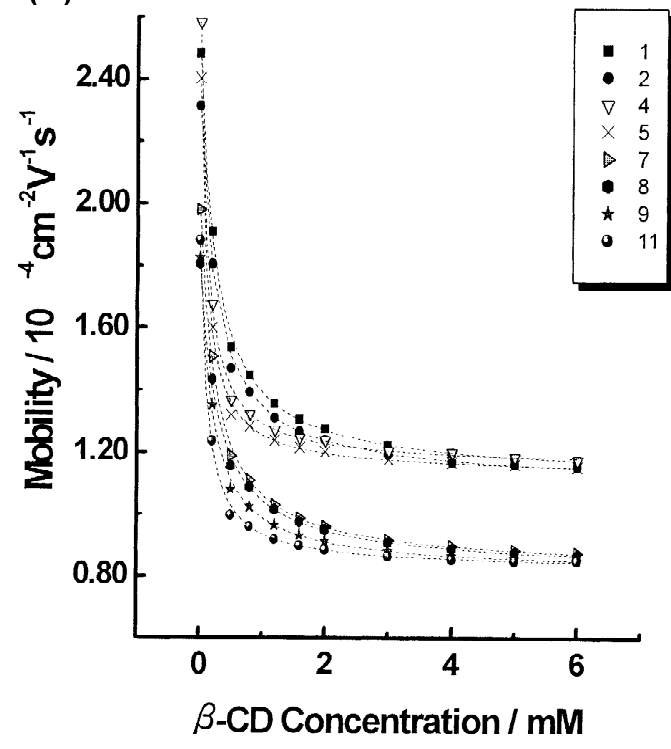

(B)

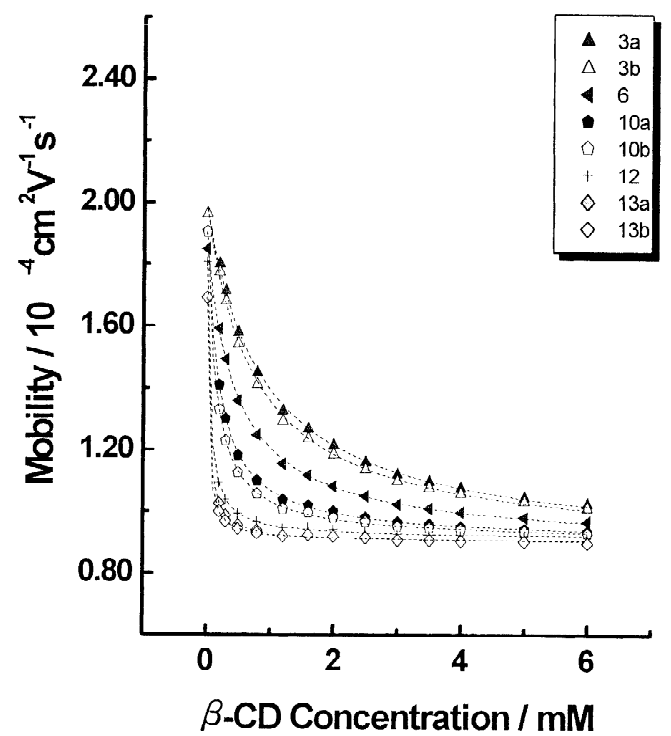

Fig. 5. Variations of the electrophoretic mobility of phenothiazines as a function of $\beta-\mathrm{CD}$ concentration in the range $0-6 \mathrm{~m} M$ using a phosphate buffer $(40 \mathrm{mM})$ at $\mathrm{pH}$ 3.0: (A) eight achiral analytes, (B) five chiral analytes. Other operating conditions and curve identification are the same as for Fig. 2.

are evaluated by curve-fitting the experimental mobility data as a function of the concentration of $\beta$-CDs at $\mathrm{pH} 3.0$ through the utilization of Microcal Origin software (version 6.0) according to Eqs. (2) and (3). The limiting electrophoretic mobility of the ionic form of an analyte $\left(\mu_{\mathrm{BH}_{2}^{2}}\right)$ is measured experimentally in the absence of $\beta$-CDs at $\mathrm{pH} 3.0$, while the trial values of $\mu_{\mathrm{BH}_{2}^{2+} \cdot \mathrm{CD}}$ are estimated from $\mu_{\mathrm{BH}_{2}^{2}}$ according to Offord's equation [28]. The mobility curve of each individual analyte as a function of $\mathrm{CD}$ concentration is then simulated by mobility curves, represented by dashed lines, and experimental data for all phenothiazines is very good. The values of binding constants and limiting mobility data determined for the inclusion complexes formed between phenothiazines and $\beta$-CDs, together with the values of $\mu_{\mathrm{BH}_{2}^{2+}}$ measured in a phosphate buffer at $\mathrm{pH}$ 3.0, are listed in Table 1.

On the other hand, in the presence of $\beta$-CDs at $\mathrm{pH}$ 3.0, the effective electrophoretic mobility of phenothiazines with piperazine substituents can be described by the following equation:

$\mu_{\mathrm{eff}}=\frac{\left[\mathrm{H}_{3} \mathrm{O}^{+}\right] \mu_{\mathrm{BH}_{3}^{3+}}+K_{\mathrm{a} 1} \mu_{\mathrm{BH}_{2}^{2+}}+K_{\mathrm{a} 1} K_{\mathrm{BH}_{2}^{+2} \cdot \mathrm{CD}}[\mathrm{CD}] \mu_{\mathrm{BH}_{2}^{2+} \cdot \mathrm{CD}}+\left[\mathrm{H}_{3} \mathrm{O}^{+}\right] K_{\mathrm{BH}_{3}^{3+} \cdot \mathrm{CD}}[\mathrm{CD}] \mu_{\mathrm{BH}_{3}^{3+} \cdot \mathrm{CD}}}{\left[\mathrm{H}_{3} \mathrm{O}^{+}\right]+K_{\mathrm{a} 1}+K_{\mathrm{a} 1} K_{\mathrm{BH}_{2}^{2+} \cdot \mathrm{CD}}[\mathrm{CD}]+\left[\mathrm{H}_{3} \mathrm{O}^{+}\right] K_{\mathrm{BH}_{3}^{3+} \cdot \mathrm{CD}}[\mathrm{CD}]}$

adjusting the values of $K_{\mathrm{BH}_{2}^{2+} \cdot \mathrm{CD}}$ and $\mu_{\mathrm{BH}_{2}^{2+} \cdot \mathrm{CD}}$ as parameters until the predicted mobility curve is bestfitted to the experimental data. As illustrated in Figs. 3 and 5, the agreement between the predicted where $\mu_{\mathrm{BH} 3^{3+}}$ and $\mu_{\mathrm{BH} 3^{3+} \cdot \mathrm{CD}}$, respectively, are the limiting electrophoretic mobility of the third protonated species of an analyte and the inclusion complexes formed between the third protonated species of an 


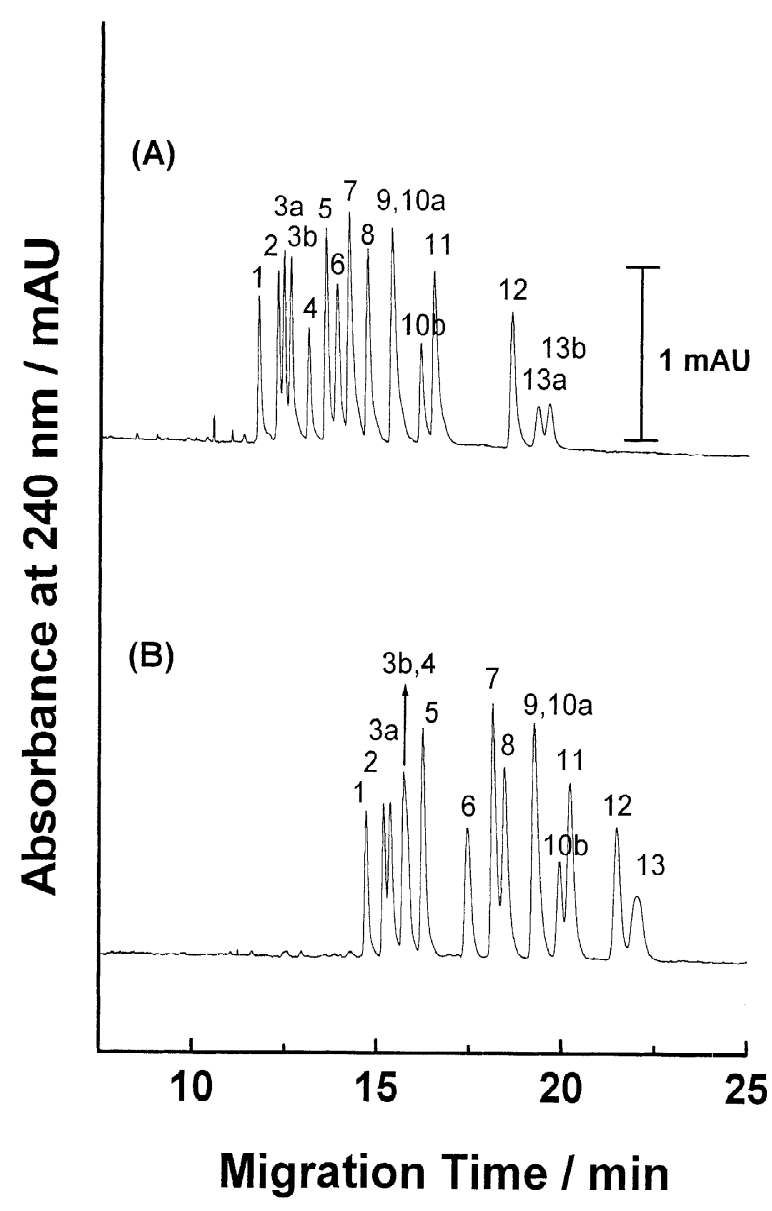

Fig. 6. Electropherograms of phenothiazines obtained with addition of $\beta-\mathrm{CD}$ at (A) $0.3 \mathrm{mM}$ and (B) $1.0 \mathrm{mM}$ using a phosphate buffer $(40 \mathrm{mM})$ at $\mathrm{pH} 3.0$.

analyte and $\beta-\mathrm{CD}, K_{\mathrm{a} 1}$ is the first acid dissociation constant of the conjugated acids, and $K_{\mathrm{BH}^{3+}}{ }^{3+} \mathrm{CD}$ is the binding constant of inclusion complexes formed between phenothiazines and $\beta$-CDs. For phenothiazines with piperazine substituents using a phosphate buffer at $\mathrm{pH} 3.0$, the concentration of free $\beta$-CDs is necessary to be corrected according to the following equation:

$[\mathrm{CD}]=\frac{[\mathrm{CD}]_{\mathrm{t}}}{1+\left(\frac{K_{\mathrm{a} 1}}{\left[\mathrm{H}_{3} \mathrm{O}^{+}\right]} K_{\mathrm{BH}_{2}^{2+} \cdot \mathrm{CD}}+K_{\mathrm{BH}_{3}^{3+} \cdot \mathrm{CD}}\right)\left[\mathrm{BH}_{3}^{3+}\right]}$ where $\left[\mathrm{BH}_{3}^{3+}\right]$ is the concentration of the third protonated species of a basic analyte.

Similarly, the binding constants and the limiting mobility of phenothiazines with piperazine substituents are evaluated by curve-fitting the experimental mobility data as a function of the concentration of $\beta$-CDs at $\mathrm{pH} 3.0$ through the utilization of Microcal Origin software according to Eqs. (4) and (5). The limiting electrophoretic mobilities of the ionic forms of an analyte $\left(\mu_{\mathrm{BH}_{2}^{2+}}\right.$ and $\left.\mu_{\mathrm{BH}_{3}^{3+}}\right)$ are determined in the absence of $\beta$-CDs at $\mathrm{pH} 3.0$, while the trial values of $\mu_{\mathrm{BH}_{2}^{2+} \cdot \mathrm{CD}}$ and $\mu_{\mathrm{BH}_{3}^{3+} \cdot \mathrm{CD}}$ are estimated from $\mu_{\mathrm{BH}_{2}^{2+}}$ and $\mu_{\mathrm{BH}_{3}^{3+}}$, respectively, according to Offord's equation [28]. The mobility curve of each individual analyte as a function of $\mathrm{CD}$ concentration is then simulated by adjusting the values of $K_{\mathrm{BH}_{2}^{2+} \cdot \mathrm{CD}}, K_{\mathrm{BH}_{3}^{3+} \cdot \mathrm{CD}}, \mu_{\mathrm{BH}_{2}^{2+} \cdot \mathrm{CD}}$ and $\mu_{\mathrm{BH}_{3}^{3+} \cdot \mathrm{CD}}$ as parameters until the predicted mobility curve is bestfitted to the experimental data. As illustrated in Fig. 3 and Fig. 5, the agreement between the predicted mobility curves, represented by dashed lines, and experimental data for all phenothiazines is very good. Table 2 lists the binding constants and limiting electrophoretic mobility of phenothiazines with piperazine substituents.

The results shown in Tables 1 and 2 indicate that the interactions of phenothiazines with $\beta$-CDs depend greatly on the types of both $R_{2}$ and $R_{10}$ substituents of phenothiazines, and the chain length of the aliphatic side chain of $\mathrm{R}_{10}$ substituents as well. Among the 13 phenothiazines studied, thioridazine interacts most strongly with $\beta$-CDs, then followed by methotrimeprazines. By comparing the binding constant evaluated for promazine with those for triflupromazine, acetopromazine and chlorpromazine, we may conclude that the binding constants of these phenothiazines with different $\mathrm{R}_{2}$ substituents follows the order $-\mathrm{CF}_{3}<-\mathrm{H}<-\mathrm{COCH}_{3}<-\mathrm{Cl}$. Moreover, by comparing either the binding constant of triflupromazine with that of trifluoperazine or the binding constant of chlorpromazine with that of prochlorperazine, we may reach a conclusion that the interactions of phenothiazines can be affected by different types of $\mathrm{R}_{10}$ substituents. Furthermore, a comparison of the binding constant of promazine with that of ethopropazine suggests that the interactions of phenothiazines with $\beta$-CDs may be in- 
Table 1

Binding constants and mobility data for phenothiazines with substituents having an aliphatic side chain and a piperidine moiety

\begin{tabular}{|c|c|c|c|c|c|}
\hline \multirow[t]{2}{*}{ Phenothiazines } & \multicolumn{2}{|l|}{$K_{\mathrm{BH}_{2}^{2+} \cdot \mathrm{CD}}$} & \multicolumn{2}{|l|}{$\mu_{\mathrm{BH}_{2}^{2+} \cdot \mathrm{CD}}$} & \multirow[t]{2}{*}{$\mu_{\mathrm{BH}_{2}^{2+}}$} \\
\hline & $\mathrm{HP}-\beta-\mathrm{CD}$ & $\beta-C D$ & $\mathrm{HP}-\beta-\mathrm{CD}$ & $\beta-C D$ & \\
\hline \multirow[t]{2}{*}{ Promethazine (3) } & $4.58 \times 10^{2}$ & $1.18 \times 10^{3}$ & 0.61 & 0.67 & 1.96 \\
\hline & $4.80 \times 10^{2}$ & $1.37 \times 10^{3}$ & 0.61 & 0.67 & 1.96 \\
\hline \multirow[t]{2}{*}{ Ethopropazine (6) } & $6.92 \times 10^{2}$ & $2.18 \times 10^{3}$ & 0.60 & 0.67 & 1.85 \\
\hline & $7.77 \times 10^{2}$ & & 0.60 & 0.67 & 1.85 \\
\hline Promazine (7) & $1.29 \times 10^{3}$ & $4.38 \times 10^{3}$ & 0.60 & 0.68 & 1.98 \\
\hline Triflupromazine (8) & $1.06 \times 10^{3}$ & $3.68 \times 10^{3}$ & 0.61 & 0.69 & 1.81 \\
\hline Acetopromazine (9) & $1.30 \times 10^{3}$ & $5.41 \times 10^{3}$ & 0.59 & 0.67 & 1.83 \\
\hline \multirow[t]{2}{*}{ Trimeprazine (10) } & $1.71 \times 10^{3}$ & $5.12 \times 10^{3}$ & 0.60 & 0.67 & 1.91 \\
\hline & $2.14 \times 10^{3}$ & $6.91 \times 10^{3}$ & 0.60 & 0.67 & 1.91 \\
\hline Chlorpromazine (11) & $2.71 \times 10^{3}$ & $1.09 \times 10^{4}$ & 0.61 & 0.69 & 1.87 \\
\hline Methotrimeprazine (12) & $7.19 \times 10^{3}$ & $1.92 \times 10^{4}$ & 0.60 & 0.67 & 1.80 \\
\hline \multirow[t]{2}{*}{ Thioridazine (13) } & $1.16 \times 10^{4}$ & $2.90 \times 10^{4}$ & 0.60 & 0.67 & 1.69 \\
\hline & $1.32 \times 10^{4}$ & $4.57 \times 10^{4}$ & 0.60 & 0.67 & 1.69 \\
\hline
\end{tabular}

Binding constant in units of $M^{-1}$ and mobility in units of $10^{-4} \mathrm{~cm}^{2} \mathrm{~V}^{-1} \mathrm{~s}^{-1}$.

Table 2

Binding constants and mobility data for phenothiazines with piperazine substituents

\begin{tabular}{|c|c|c|c|c|c|c|c|c|c|c|}
\hline \multirow[t]{2}{*}{ Phenothiazines } & \multicolumn{2}{|l|}{$K_{\mathrm{BH}_{2}^{2+} \cdot \mathrm{CD}}$} & \multicolumn{2}{|l|}{$K_{\mathrm{BH}_{3}^{3} \cdot \cdot \mathrm{CD}}$} & \multicolumn{2}{|l|}{$\underline{\mu_{\mathrm{BH}_{2}^{2+} \cdot \mathrm{CD}}}$} & \multicolumn{2}{|l|}{$\mu_{\mathrm{BH}_{3}^{3+} \cdot \mathrm{CD}}$} & \multirow[t]{2}{*}{$\mu_{\mathrm{BH}_{2}^{2+}}$} & \multirow[t]{2}{*}{$\mu_{\mathrm{BH}_{3}^{3}+}$} \\
\hline & $\mathrm{HP}-\beta-\mathrm{CD}$ & $\beta-C D$ & $\mathrm{HP}-\beta-\mathrm{CD}$ & $\beta-C D$ & $\mathrm{HP}-\beta-\mathrm{CD}$ & $\beta-C D$ & $\mathrm{HP}-\beta-\mathrm{CD}$ & $\beta-C D$ & & \\
\hline Trifluoperazine (1) & $3.0 \times 10^{2}$ & $1.2 \times 10^{3}$ & $6.0 \times 10^{2}$ & $2.5 \times 10^{3}$ & 0.58 & 0.68 & 0.96 & 1.14 & 1.60 & 2.70 \\
\hline Fluphenazine (2) & $3.0 \times 10^{2}$ & $1.2 \times 10^{3}$ & $6.0 \times 10^{2}$ & $2.45 \times 10^{3}$ & 0.58 & 0.66 & 0.97 & 1.13 & 1.45 & 2.55 \\
\hline Prochlorperazine (4) & $8.5 \times 10^{2}$ & $3.5 \times 10^{3}$ & $1.85 \times 10^{3}$ & $7.5 \times 10^{3}$ & 0.61 & 0.68 & 1.01 & 1.16 & 1.54 & 2.74 \\
\hline Perphenazine (5) & $8.5 \times 10^{2}$ & $3.5 \times 10^{3}$ & $1.85 \times 10^{3}$ & $7.5 \times 10^{3}$ & 0.62 & 0.68 & 1.02 & 1.16 & 1.54 & 2.65 \\
\hline
\end{tabular}

Binding constant in units of $M^{-1}$ and mobility in units of $10^{-4} \mathrm{~cm}^{2} \mathrm{~V}^{-1} \mathrm{~S}^{-1}$.

fluenced by the chain length of the aliphatic side chain of $\mathrm{R}_{10}$ substituents.

It should be pointed out that hydrogen bonding interaction plays an important role in the separation of phenothiazine derivatives and the chiral recognition of the enantiomers of phenothiazines which has been previously described [21]. In views of the structures of inclusion complexes formed between phenothiazines and $\beta-C D$, which suggested that approximately one-half of the phenothiazine ring was embedded in the cavity of $\beta-\mathrm{CD}$ and that the other half of the phenothiazine ring, together with the $R_{2}$ and $R_{10}$ substituents, was located outside the cavity of $\beta-C D[29,30]$, the results obtained for phenothiazines with substituents having different aliphatic side chains reveal that a hydrogen bond may be formed between the nitrogen atom of the aliphatic side chain of the $\mathrm{R}_{10}$ substituent and the hydroxy group of $\beta$-CDs located at the rim of the $\beta-C D$ cavity. Thus the interactions of phenothiazines with $\beta$-CDs depend also on the chain length of the aliphatic side chain of the $\mathrm{R}_{10}$ substituent.

\section{Conclusion}

Effective separation of 13 phenothiazines was achieved with a phosphate buffer containing $\beta$-CDs at a concentration less than $0.5 \mathrm{~m} M$ at $\mathrm{pH} 3.0$. The determination of $\mathrm{p} K_{\mathrm{a}}$ values of phenothiazines allows us to rationalize the influence of buffer $\mathrm{pH}$ on the selectivity and migration behavior of phenothiazines. 
The results of the evaluation of binding constants of phenothiazines to $\beta$-CDs reveal that the interactions of phenothiazines with $\beta$-CDs depend on the types of $R_{2}$ and $R_{10}$ substituents of phenothiazines, and the chain length of the aliphatic side chain of $R_{10}$ substituents as well. The selectivity and migration behavior of phenothiazines are greatly influenced by the interactions of phenothiazines with $\beta-C D s$, in which hydrogen bonding may play a significant role.

\section{Acknowledgements}

We thank the National Science Council of ROC in Taiwan for financial support.

\section{References}

[1] S. Fanali, J. Chromatogr. A 875 (2000) 89.

[2] Gy. Vigh, A.D. Sokolowski, Electrophoresis 18 (1997) 2305.

[3] S. Fanali, J. Chromatogr. A 792 (1997) 227.

[4] S. Li, W.C. Purdy, J. Pharm. Biomed. Anal. 49 (1991) 409.

[5] S. Piperaki, A. Perakis, M. Parissi-Poulou, J. Chromatogr. A 660 (1994) 339.

[6] A.A.L. Van Overbeke, W.R.G. Baeyens, A. Beyaert, H.Y. Aboul-Enein, H. Oda, J. Liq. Chromatogr. 20 (1997) 693.

[7] E. Ameyibor, J.T. Stewart, J. Liq. Chromatogr. 20 (1997) 855.

[8] H. Makamba, V. Andrisano, R. Gotti, V. Cavrini, G. Felix, J. Chromatogr. A 818 (1998) 43.

[9] D.T. Witte, R.A. de Aeeuw, B.F.H. Frenth, J. High Resolut. Chromatogr. 13 (1990) 569.
[10] G. Diehl, U. Karst, J. Chromatogr. A 890 (2000) 281.

[11] M. Beljean, A.M. Siouffi, J. Chromatogr. Sci. 39 (2001) 229.

[12] P.G.H.M. Muijselaar, H.A. Claessens, C.A. Cramers, J. Chromatogr. A 735 (1996) 395.

[13] A. Aumatell, R.J. Wells, J. Chromatogr. B 669 (1995) 331.

[14] R.Y. Wang, X.N. Lu, M.J. Wu, E.K. Wang, J. Chromatogr. B 721 (1999) 327.

[15] S. Busch, J.C. Kraak, H. Poppe, J. Chromatogr. 635 (1993) 119.

[16] X.X. Zhang, F. Hong, W.B. Chang, Y.X. Ci, Y.H. Ye, Anal. Chim. Acta 392 (1999) 175.

[17] T. de Boer, R. Bijma, K. Ensing, J. Capillary Electrophor. 5 (1998) 65

[18] F. Wang, M.G. Khaledi, Anal. Chem. 68 (1996) 3460.

[19] R. Wang, X. Lu, H. Xin, M. Wu, Chromatographia 51 (2000) 29.

[20] B. Chankvetadze, I. Kartozia, N. Burjanadze, D. Bergenthal, H. Luftmann, G. Blaschke, Chromatographia 53 (2001) S290.

[21] C.E. Lin, K.H. Chen, J. Chromatogr. A 930 (2001) 155.

[22] C.E. Lin, K.H. Chen, Y.Y. Hsiao, W.S. Liao, C.C. Chen, J. Chromatogr. A 971 (2002) 261.

[23] S.C. Smith, M.G. Khaledi, Anal. Chem. 65 (1993) 193.

[24] C.E. Lin, W.S. Liao, K.H. Chen, W.Y. Lin, J. Chromatogr. A, submitted.

[25] S.A.C. Wren, R.C. Rowe, J. Chromatogr. 603 (1992) 235.

[26] C.E. Lin, W.C. Lin, W.C. Chiou, E.C. Lin, C.C. Chang, J. Chromatogr. A 755 (1996) 261.

[27] C.E. Lin, H.C. Huang, H.W. Chen, J. Chromatogr. A 917 (2000) 297.

[28] R.E. Offord, Nature 5049 (1966) 591.

[29] S. Piperaki, A. Perakis, M. Parissi-Poulou, J. Chromatogr. A 660 (1994) 339.

[30] Q.X. Guo, H.Y. Liu, X.Q. Ruan, X.Q. Zhang, Y.Y. Shi, Y.C. Lin, J. Incl. Phenom. 35 (1999) 487. 